\section{European synchrotron source}

\section{Strasbourg and Grenoble battle for site}

THE European Synchrotron Radiation Source (ESRS), a world-rank $5 \mathrm{GeV}$ electron synchrotron first planned and championed in the late 1970 s by the European Science Foundation (ESF), seems likely to be built at last, at Strasbourg on the Franco-German border. Or so the auguries suggested last week, in the midst of an extraordinary political and "scientific" battle now raging between the little tourist town of Strasbourg and the French alpine city of Grenoble, both potential sites for ESRS.

The battle is all the more extraordinary after the years ESRS has spent in the wilderness. The idea for an intense nextgeneration synchrotron radiation source was first canvassed in 1979, when ESF (a consortium of European research councils) began touting its technical study around Europe - without success. But now, partly as the result of a poll showing a potential ESRS user community of 2,000 scientists and 600 research groups in Europe, and much interest in industry, Cinderella has become the belle of the ball.

In the latest move, the French and German research ministers have reached a deal that will place ESRS in France and (as compensation) a "European trans-sonic wind tunnel" in Cologne, West Germany. (Britain was originally in the running for ESRS, but dropped out because of the high expenditure expected of successful bidders.)

Now, with the main battle settled in favour of France, the two regional governments that might benefit have raised the stakes by throwing money (and glossy brochures) at the project. Strasbourg, the home of ESF, has bid FF 100 million ( $£ 85$ million) to win the project, and Grenoble has offered FF 80 million ( $£ 65$ million) towards the FF 900 million ( $£ 750$ million) cost of the machine. If ESRS were built at Grenoble, it would go alongside the highflux neutron beam facility, the Institut Laue-Langevin (ILL), which is insisting that the "scientific case" would favour such a link.

French regional, economic and scientific policy, however, favours Strasbourg. And this is a powerful force in Paris at present, with the government seeking to decentralize and to create new regional centres of excellence. Strasbourg is also more centrally located in Europe, which is why West Germany favours it. Although Britain would prefer Grenoble, its lack of cash gives it no leverage. The choice now rests with the French Goverment. Paris sources say that Strasbourg is the likely but not certain bet in a decision that should be taken in a few weeks.
On the scientific side, the battle for ESRS appears at first sight to be between the biologists (in whose discipline the University of Strasbourg and surrounding institutes excel) and the physicists (where Grenoble is on a level with Paris).

But do the biologists want the machine? Some say yes, some say no. The directorate of the major French research council, the Centre National de la Recherche Scientifique (CNRS), wants ESRS for the biologists and so favours Strasbourg, where CNRS already runs a centre for low-energy nuclear physics and a number of important laboratories in molecular biology and where it plans a major research centre in plant biology. Many individual CNRS biologists, however, have a different view: they would prefer that ESRS stayed with the physicists in Grenoble.

According to CNRS, a Strasbourg location for ESRS would help biologists (and chemists) to become more involved with the use of synchrotron radiation and break down interdisciplinary barriers. It

\section{Marinov}

BRITISH diplomatic missions in Genoa (Italy) and Vienna (Austria) have been under siege in the past few weeks by $\mathrm{Dr}$ Stefan Marinov, the Bulgarian physicist now living in the West, with threats of selfimmolation. Dr Marinov is protesting at the refusal of the Editor of Nature to publish three long scientific articles, one of which is a restatement of Marinov's theory of absolute space-time, another of which announces the design of a perpetuum mobile.

Dr Marinov first embarked on selfimmolation in Genoa on 8 August, outside the British Consulate, but by his own account was held in conversation for half an hour by staff from the consulate and was compelled to flee when the staff sought the assistance of the police, knowing that he was present illegally in Italy (having been denied entry in 1980).

At a press conference held in Austria last week, Dr Marinov again announced his plan for self-immolation, this time outside the British Embassy in Vienna. On the telephone earlier this week, he said that he would take this step at $10 \mathrm{a} . \mathrm{m}$. local time on 2 October but, on being informed of the appearance of this piece, said "Now I don't know whether to immolate myself tomorrow"'.

Dr Marinov's claims that Einstein's theory of special relativity is misplaced were first made in 1974 (Czechoslovak J.

would also contribute to the development of Strasbourg as a centre of European science, close to West Germany and Swiss centres. CNRS biologists are worried about having to help pay for a facility that in practice they will not use. They say their budget within CNRS is already tight, burdened as it is with more than their share of an existing French synchrotron source (LURE) at Orsay, whence their preference for Grenoble.

The director of the European Molecular Biology Laboratory (EMBL) at Heidelberg is said also to be in favour of Grenoble, where EMBL has a neutron scattering facility. ILL's own case is that its own work - the instrumentation as well as scientific interests - is similar but complementary to that of ESRS, so that a Grenoble site for ESRS (or "Maxwell Institute" as ILL has already dubbed it) would be more productive than at Strasbourg. ILL says there is room (just) on its compact site for the 772-metre-circumference synchrotron, and that vibration from the nearby autoroute should not be the nuisance once feared.

Grenoble's case is strong, but Strasbourg has politics on its side. No wonder that the French science minister, Hubert Curien, says that the decision "is not proving easy".

\title{
Further threat of immolation
}

Phys. B24, 965; 1974), on the basis of an experiment carried out in Bulgaria that purported to show that the velocity of light is direction-dependent. Marinov has since claimed to have repeated the experiment. The paper describing that investigation, "New measurement of the Earth's absolute velocity with the help of the coupled shutters experiment", says that the experiment was carried out in his girlfriend's apartment, that the rotating shutters, functioning as a siren, disturbed the neighbours and that "after a couple of altercations, my girl-friend threw away from her apartment not only my apparatus but also me".

The two other papers submitted for publication are called "On the action and interaction of stationary currents" and "Coup de grace to special relativity and to something else". All three papers have now been published by Marinov in his book The Thorny Way to Truth (Part II).

Marinov's complaint against Nature is primarily that publication of these three papers has been refused, but also that "milliards of dollars" are being lost each day the world remains ignorant of his perpectual motion machine. Other matters in dispute are Nature's refusal to publish an appeal to the late Yuri Andropov at the end of last year and, earlier, a manifesto called the "Ten Jena Commandments".

John Maddox 